\title{
ODOUR MEASUREMENT IN WASTEWATER TREATMENT PLANT USING BOTH EUROPEAN AND JAPANESE STANDARDIZED METHODS: CORRELATION AND COMPARISON STUDY
}

\author{
NADDEO V. ${ }^{1}$ \\ ZARRA T. ${ }^{1}$ \\ KUBO A. ${ }^{2}$ \\ UCHIDA N. ${ }^{2}$ \\ HIGUCHIT. ${ }^{2}$ \\ BELGIORNO V. ${ }^{1}$
}

\author{
${ }^{1}$ Università degli Studi di Salerno \\ Department of Civil Engineering \\ Sanitary Environmental Engineering Division (SEED) \\ Via Giovanni Paolo II, 132, 84084 Fisciano (SA), Italy \\ ${ }^{2}$ Yamaguchi University \\ Graduate School of Science and Engineering \\ 2-16-1, Tokiwadai, Ube \\ Yamaguchi 755-8611, Japan
}

Received: 22/07/2016

Accepted: 08/09/2016

*to whom all correspondence should be addressed:

Available online: $12 / 10 / 2016$

\section{ABSTRACT}

Odours discharged from wastewater treatment plants generally cause severe damage to locals. When facility odors affect air quality and cause citizen complaints, an investigation of those odours may require using standardized scientific methods. Odour intensity is one of the main odour characterization parameter, and represents an important sensory indicator of environmental odours.

Presently, different international standards have been developed for the measurement of odours. Main consolidated methods are the measurement of odour index assessed by panelists, standardized in Japan and developed there more than 40 years ago; and the measured of odour concentration by dynamic olfactometer according to European standard EN13725:2003.

In this study odour samples were collected on a municipal wastewater treatment plant to investigate the relationship between odour index assessed by Japanese standard methods and odour concentration measured with dynamic olfactometry. A monthly sampling and relative odour measurement were carried out for consecutive 8 months at the Laboratory of the Sanitary Environmental Engineering Division (SEED) at the University of Salerno (Italy).

Results show a strong linear correlation between the two investigated odour measurement methods, in the case of the measurement of high concentrations. While at lower odour concentrations were observed a difference between the two methods.

Keywords: dynamic olfactometry, EN13725:2003, human assessor, odor concentration, triangle odor bag method.

\section{Introduction}

Wastewater treatment plants (WWTPs) are considered one of the main odour sources in urbanized area (Stuetz et al., 2001; Gostelow et al., 2001; Zarra et al., 2008; Giuliani et al., 2015). Odour measurements are essential for odour regulation and control (Ueno et al., 2009). The principal parameter that is determined with a measure of odour is her concentration (Belgiorno et al., 2012).

Naddeo V., Zarra T., Kubo A., Uchida N., Higuchi T. and Belgiorno V. (2016), Odour measurement in wastewater treatment plant using both European and Japanese standardized methods: correlation and comparison study, Global NEST Journal, 18(4), 728-733. 
The concentration of an ambient odour or a odorous substances are generally carried out through two steps: a first sampling phase and a subsequent analysis phase (Belgiorno et al., 2012; Zarra et al., 2012). For the sampling of odours there are few references and the existing ones don't define univocally all aspects (Zarra et al., 2014). On the contrary, for the odour analysis there are several international guidelines or standards which indicate a standardized procedure (Nicell, 2009; Sironi et al., 2012).

In Europe, odour analyses are performed by introducing an odour sample to screened panel members using dynamic olfactometry according (Zarra et al., 2012). There are currently several different methods for dynamic olfactometry analysis that are universally used. In several countries from Europe (EN13725: 2003) to North America (USA ASTM 679-04: 2011), including Australia and New Zealand (AS/NZS4323:2001), there are standardised methods that are commonly used for dynamic olfactometry (DO) analysis (Bokowa et al., 2014; Dincer et al., 2006). All of these methods use a decreasing dilution series to determine an odour detection threshold value (Bokowa et al., 2014).

On the other hand, in several Asian countries, an increasing dilution series is used for odour evaluations. The triangle odour bag method (TOBM) is an olfactory method to measure odour concentration, which has been adopted for the offensive odour control law in Japan described in the "Odour Index Regulation and Triangular Odour Bag Method" and the document: GB/T14675-93 guideline. (lawasaki, 2003; Bokowa et al., 2014; Zarra et al., 2012).

All of these methods determine the odour concentration by sniffing diluted air samples. However the dilution equipment, estimation methods of the threshold and panel selection procedures are different (Higuchi et al., 2004; Ueno et al., 2009).

In this paper, the relationship between odour concentration emitted by WWTP assessed by Japanese standard methods and odour concentration measured with dynamic olfactometry according to European standard EN13725:2003 are discussed.

\section{Materials and methods}

\subsection{Experimental program}

Research studies were carried out at conventional WWTP designed for 700.000 PE, located in the industrial area of the municipality of Salerno, in the Campania Region (Southern Italy). The principal design characteristics of the Salerno WWTP are shown in Table 1.

Table 1. Design characteristics of the Salerno WWTP.

\begin{tabular}{|c|c|}
\hline Parameter & Salerno WWTP \\
\hline hydraulic load* & $280 \mathrm{l} / \mathrm{ab} \cdot \mathrm{d}$ \\
\hline organic load* & $80 \mathrm{~g} \mathrm{BOD}_{5} / \mathrm{ab} \cdot \mathrm{d}$ \\
\hline average daily flow** & $106^{\prime} 000 \mathrm{~m}^{3} \mathrm{~d}^{-1}$ \\
\hline $\mathrm{BOD}_{5} * *$ & $350 \mathrm{mg} \mathrm{l}^{-1}$ \\
\hline $\mathrm{COD}^{* *}$ & $780 \mathrm{mg} \mathrm{l}^{-1}$ \\
\hline $\mathrm{SST}^{* *}$ & $580 \mathrm{mg} \mathrm{l}^{-1}$ \\
\hline primary sludge extraction** & $680 \mathrm{~m}^{3} \mathrm{~d}^{-1}$ \\
\hline secondary sludge extraction** & $2100 \mathrm{~m}^{3} \mathrm{~d}^{-1}$ \\
\hline dewatered sludge production** & $44 \mathrm{~m}^{3} \mathrm{~d}^{-1}$ \\
\hline
\end{tabular}

*design data; **average operating data for the year 2015

To investigate the correlation between the two methods were selected four treatment units of the plant which present the highest odour emissions according to previous studies (Zarra et al., 2008): grit channel (P1), primary sedimentation (P2), aeration basin (P3), sludge dewatering (P4) (Figure 1). Air samples were collected one a month for eight consecutive months at each sampling point. A total of 32 samples were collected over the research period. For each month, all four samples were taken during the same day in 
stable meteorological conditions with not significant wind speed. During the sampling program the WWTP was operating with an average daily flow of $8000 \mathrm{~m}^{3} \mathrm{~h}^{-1}$.

Air samples were collected according to the methods recognized by the technical-scientific literature, using the 'lung' technique, whereby the sampling bag is placed inside a rigid container, and the container evacuated using a vacuum pump. Nalophan ${ }^{\circledR}$ sampling bags with 20 liters volume are used for the sampling.

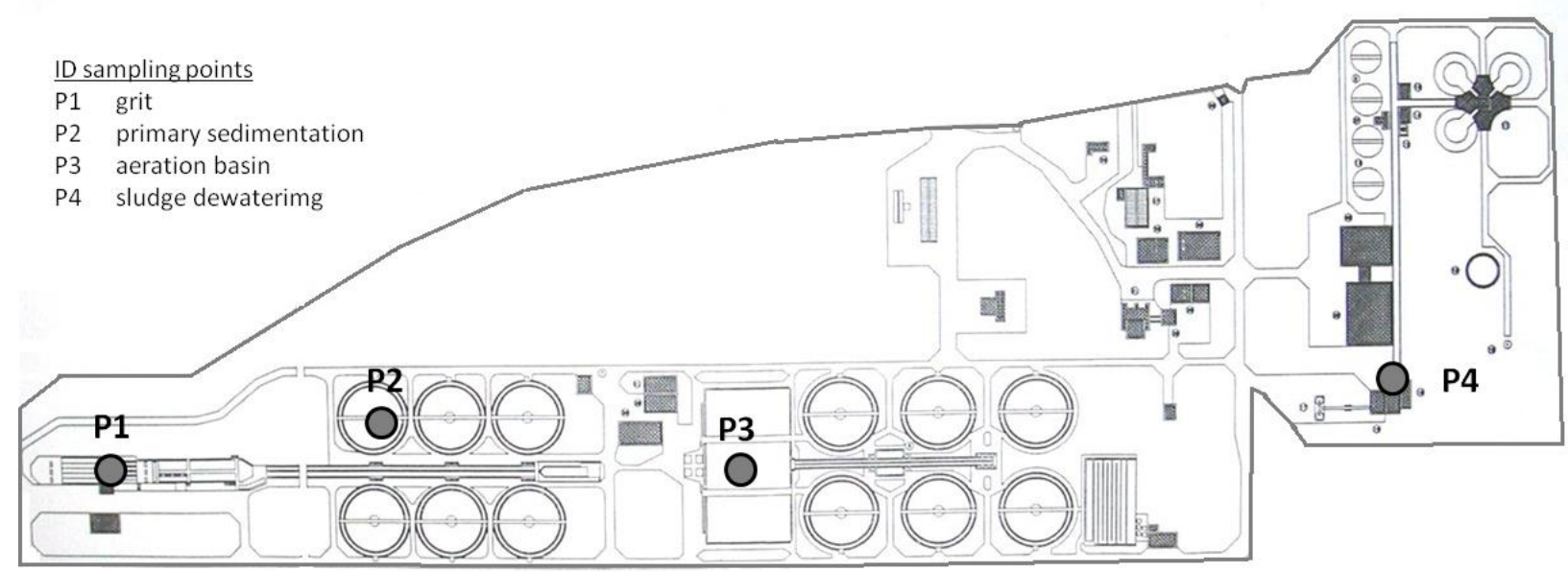

Figure 1. Sampling points at Salerno WWTP

\subsection{Analysis}

Air samples, collected during the sampling program at WWTP, were characterized by both dynamic olfactometry (DO) and triangular odour bag methods (TOBM) at the SEED Laboratory of the University of Salerno.

DO analyses were conducted using the dynamic olfactometer TO8 (ECOMA, GmbH) with the "yes/no" method for the measurement of Odour Concentrations $\left(\mathrm{C}_{\mathrm{od}}\right)$.

Odour concentrations $\left(\mathrm{C}_{\mathrm{od}}\right)$ were also measured by the triangle odour bag method according to Japanese offensive odour control law.

All samples were analysed within 14 hours after sampling, according to Zarra et al. studies (2012a). Odour measurements were carried out by the same group of panellists, in order to minimize any deviation caused by other factors than the test methods. The results were compared in terms of Odour Index (OI), calculated with the following equation:

$$
\mathrm{OI}=10 \log (\operatorname{Cod})
$$

\section{Results and discussion}

\subsection{Comparison studies}

Variability of odour index measured with both methods at each investigated sampling point of WWTP is represented in Figure 2 and Figure 3 with a Box-Whisker Plots. Figure 2 reports the odour index determined with the data of the measures detected in all the investigated points, for the comparison of the two methods. While Figure 3 show the variability of the two methods for each investigated sampling point. 


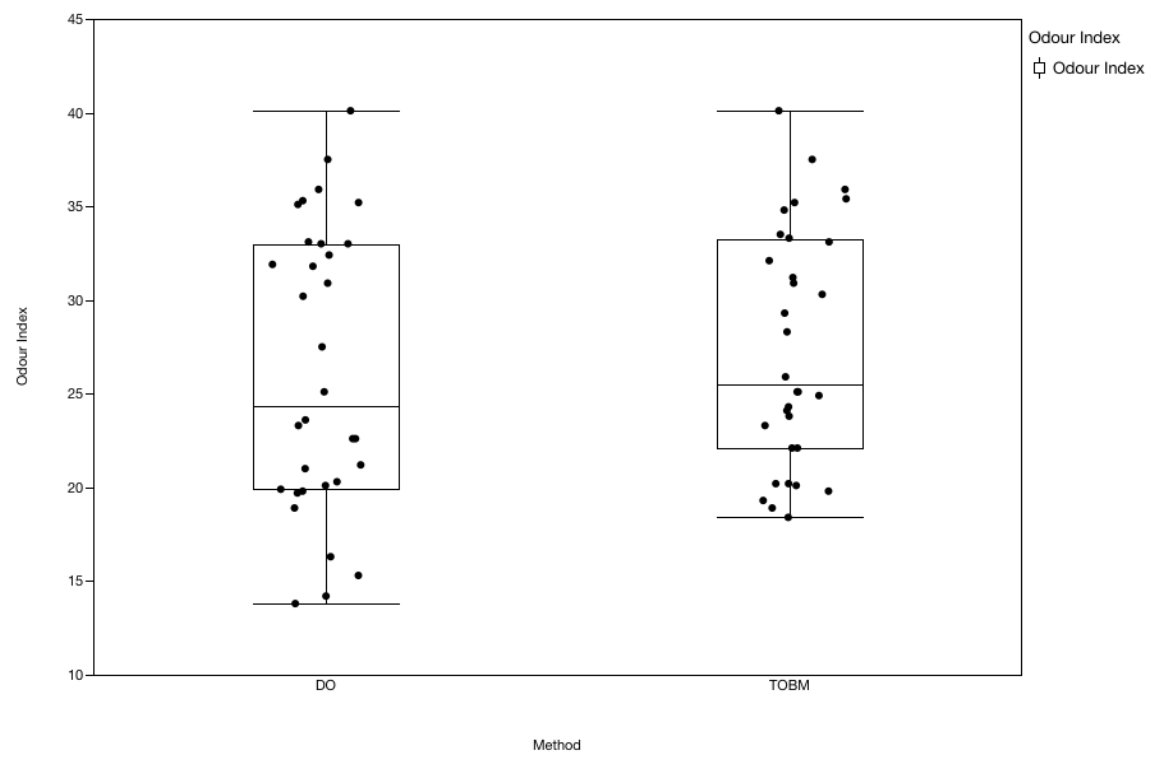

Figure 2. Box-Whisker diagrams of odour index determined withall measured data at WWTP for both methods

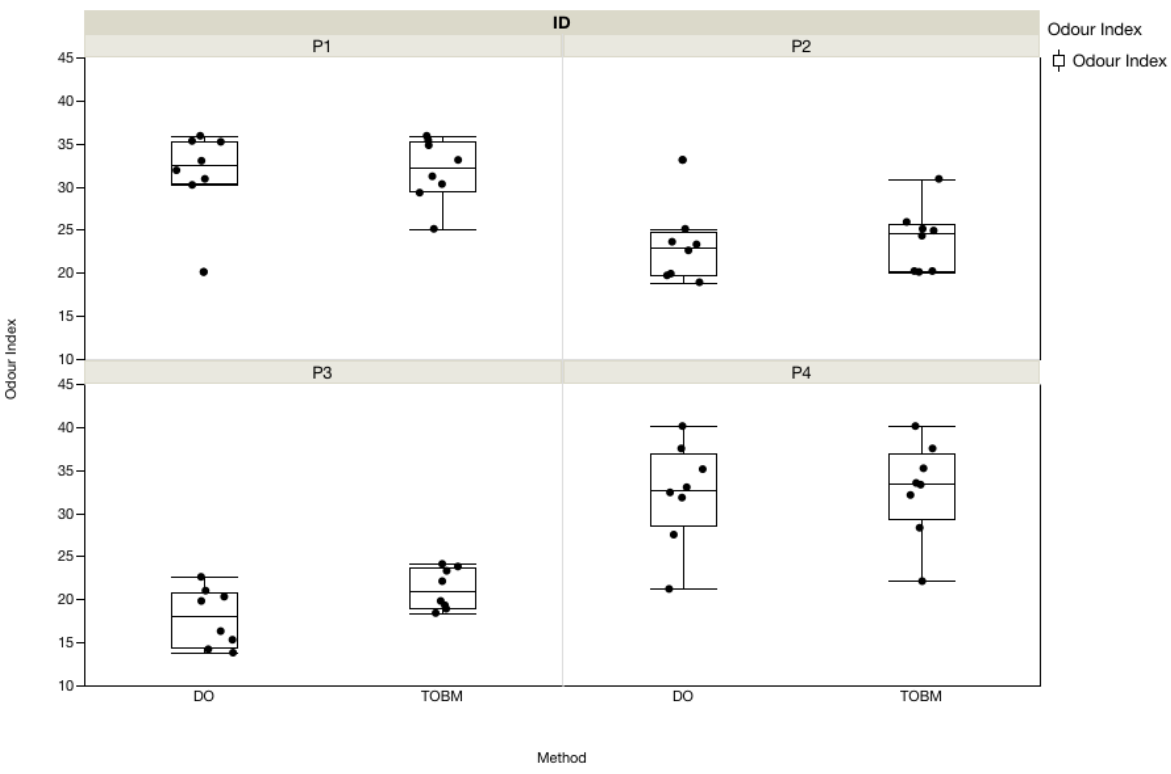

Figure 3. Box-Whisker diagrams of odour index determined for each investigated point for both methods

Considering all measurement carried out at WWTP, the results shown greater variability of DO versus TOBM respectively with odour index ranged from 13,8 to 40,0 for DO and from to 18,4 to 40,1 for TOBM. While analyzing the variability of the two methods for each investigated point we see how P2 and P3 are characterized by lower concentration of odour in both methods and for these investigated units the results highlight a major divergence between the methods. The same methods show a better match of the measures for the samples from sources P1 and P4, characterized with an odour index generally greater than 25.

\subsection{Correlation studies}

Figure 4 show the correlation between the DO and the TOBM method. 


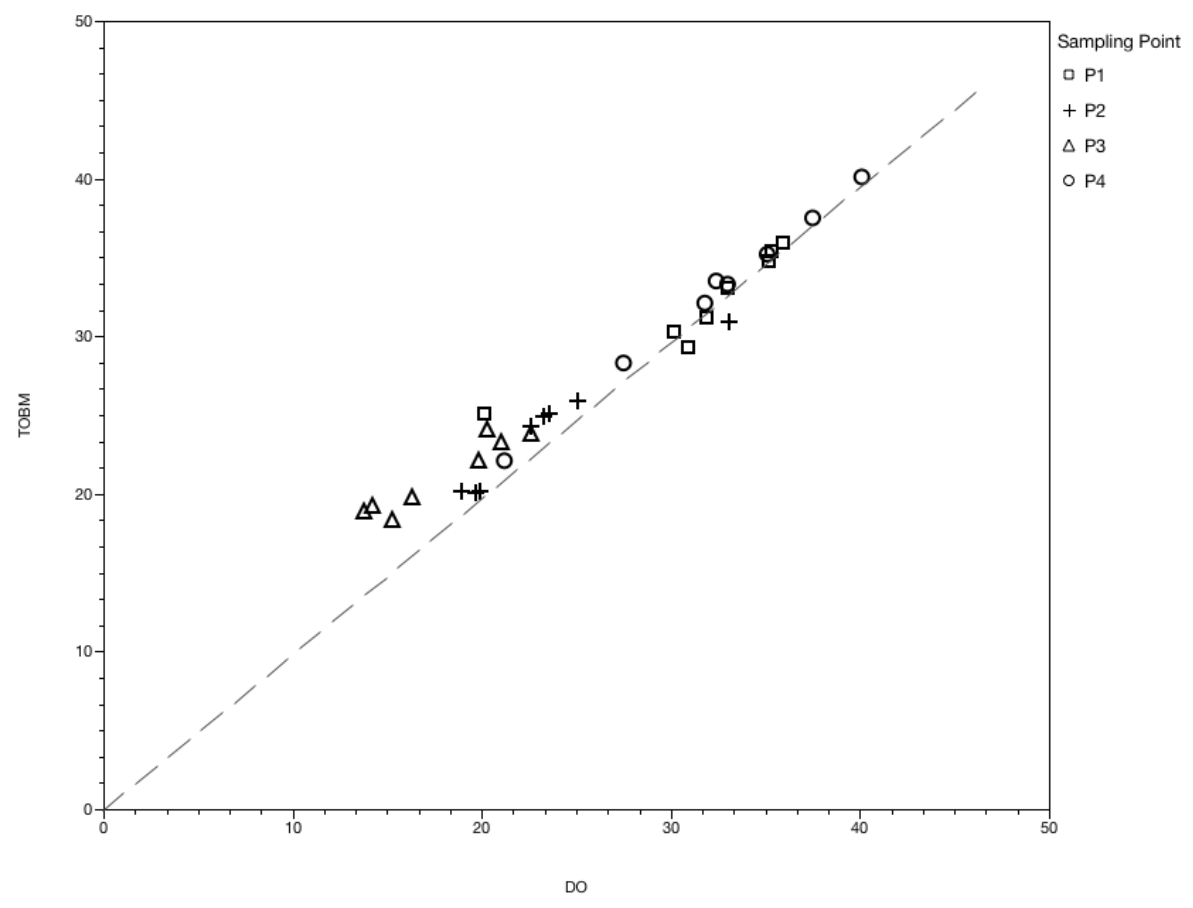

Figure 4. Correlation between the Odour Index measured by DO and TOBM.

Results highlights a strong correlation $\left(R^{2}=0,987\right)$. However, as observed by analyzing the individual sampling points, the correlation between the TOBM and the DO is lower for samples with concentrations less than $100 \mathrm{OU} \mathrm{m}^{-3}$ (corresponding to 20 odour index). For samples with lower concentration, the dynamic olfactometry highlight less affability and repeatability of measurements. While there are not significant differences between the DO and the TOBM with odour concentration greater than 30 odour index (corresponding to $1000 \mathrm{OU} \mathrm{m}^{-3}$ ).

\section{Conclusions}

Odour concentrations detected from air samples analyzed by the triangle odour bag method (TOBM) show comparable results respect of samples measured by the dynamic olfactometry (DO) for the sources with higher odour concentration.

Dynamic olfactometry highlight less affability and repeatability of measurements for samples with lower concentrations, versus the TOBM method. However the implementation of the TOBM method require longer analysis times for the preparation and for the number of the samples to analyze.

\section{References}

ASTM 679-04, Standard Practice for Determination of Odor and Taste Thresholds by a Forced Choice Ascending Concentration Series Method of Limits.

Australian/New Zealand AS/NZS4323:2001 Standard (2001), Stationary Source Emissions, Part 3: Determination of Odour Concentration by Dynamic Olfactometry.

Belgiorno V., Naddeo V. and Zarra T. (2012), Odour Impact Assessment Handbook, Wiley \& Son. London. ISBN: 9781-119-96928-0.

Bokowa A. H. and Bokowa M. (2014), Comparing the Accuracy of Three Odour Analysis Techniques Used in Europe, North America, Australia, New Zealand and Asia, Chemical engineering transactions, 40, 1-6. doi: 10.3303/cet 1440001.

Dincer F. and Muezzinouglu A. (2006), Chemical characterization of odors due to some industrial and urban facilities in Izmir, Turkey, Atmospheric Environment, 40(22), 4210-4219. 
EN 13725:2003 (2003), Air Quality e Determination of Odour Concentration by Dynamic Olfactometry, Comité Européen de Normalisation, Brussels, 1 - 70.

Giuliani S., Zarra T., Naddeo V. and Belgiorno V. (2015), A novel tool for odor emission assessment in wastewater treatment plant, Desalination and Water Treatment, 55(3), 712-717.

Gostelow P., Parsons S.A. and Stuetz R.M. (2001), Review paper, Odour measurements for sewage treatment works, Water Research, 35(3), 579-597.

Higuchi T. and Masusa J. (2004), Interlaboratory comparison of olfactometry in Japan, Water Science and Technology 50(4), 147-152.

Iwasaki Y. (2003), Odor measurement review, Office of Odor, Noise and Vibration Environmental Management Bureau Ministry of the Environment Government of Japan, 37-47.

Nicell J.A. (2009), Assessment and regulation of odour impacts, Atmospheric Environment, 43, 196-206.

Odor Index Regulation and Triangular Odor Bag Method (2003), Office of Odor, Noise and Vibration Environmental Management Bureau Ministry of the Environment Government of Japan.

Sironi S., Capelli L., Dentoni L. and Del Rosso R. (2012), Odour Regulation and Policies in in Odour Impact Assessment Handbook, Wiley \& Son. London. ISBN: 978-1-119-96928-0, 175-186.

Ueno H., Amano S., Merecka B. and Kośmider J. (2009), Difference in the odor concentrations measured by the triangle odor bag method and dynamic olfactometry, Water Science and Technology 59(7), 1339-1342. doi: 10.2166/wst.2009.112.

Stuetz R. and Frechen F.B. (2001), Odours in wastewater treatment: measurement, modelling and control, IWA Publishing, ISBN: 1900222469.

Zarra T., Naddeo V., Belgiorno V., Reiser M. and Kranert M. (2008), Odour monitoring of small wastewater treatment plant located in sensitive environment, Water Science and Technology, 58(1), 89-94.

Zarra T., Naddeo V., Belgiorno V., Higuchi T., Dutta N. and Bhuyan M. (2012), Instruments and Methods for Odour Sampling and Measurement. John Wiley \& Sons, Inc., ISBN: 9781119969280, 31-83.

Zarra T., Reiser M., Naddeo V., Belgiorno V. and Kranert M. (2012a), A comparative and critical evaluation of different sampling materials in the measurement of odour concentration by dynamic olfactometry, Chemical Engineering Transactions, 30, 307-312.

Zarra T., Reiser M., Naddeo V., Belgiorno V. and Kranert M. (2014), Odour Emissions Characterization from Wastewater Treatment Plants by Different Measurement Methods, Chemical Engineering Transactions, 40, 37-42. 